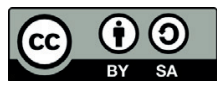

\title{
ARTIFICIAL INTELLIGENCE TRAINING - APPROACHES, RESULTS, ANALYSES AND CONCLUSIONS
}

\author{
Veneta Tabakova-Komsalova ${ }^{1}$, Todorka Glushkova ${ }^{2}$, \\ Stanimir Stoyanov ${ }^{3}$, \& Irina Krasteva ${ }^{4}$ \\ Plovdiv University "Paisii Hilendarski", 4000 Plovdiv, 24 "Tzar Asen" str., \\ Bulgaria \\ ${ }^{1}$ veni tab@abv.bg, ORCID 0000-0002-0617-9844 \\ 22. glushkova@uni-plovdiv.bg, ORCID 0000-0002-6243-9364 \\ ${ }^{3}$ stani@uni-plovdiv.net, ORCID 0000-0002-3854-4260 \\ ${ }^{4}$ krasteva@uni-plovdiv.bg, ORCID 0000-0003-0842-8143
}

\begin{abstract}
The development of the digital society is directly related to the training and use of algorithms and concepts of artificial intelligence. Packages of strategic documents have been developed at European and national level, which set as a main goal for education the introduction of elements of artificial intelligence in different educational levels and forms of education. In recent years, experimental training in artificial intelligence (AI) has been applied in school education in Bulgaria. New approaches are also applied in the training of computer science students. The report addresses some issues and challenges in organizing and conducting this training. Some guidelines and approaches for creating an appropriate curriculum in the field of knowledge structuring and semantic modelling are outlined. As a result of the conducted experimental training, it was established that this subject can be successfully studied in secondary school.
\end{abstract}

Keywords: artificial intelligence, logic programming, knowledge structuring and semantic modelling.

\section{INTRODUCTION}

The logic in the development of our civilization follows the tendency of constant rise, passing first through the Agrarian, and then through the First, Second and Third Industrial revolutions. Following this trend, the Fourth Industrial Revolution (Schwab, 2016) today sets twenty-three turning points in the digital age. Almost all changes are related to the application and development of computational thinking and artificial intelligence. This makes the requirement for educational systems to build these key 
competencies, knowledge and skills in all educational levels more and more relevant (Tuomi, 2018).

To achieve these goals, packages of strategic documents have been created at global, European and national levels, concerning the study of artificial intelligence (AI) and the development of computational thinking. Despite the requirements and expectations of the digital society, the experience in studying AI (especially in school education) worldwide is insufficient. This motivates us to share our experience in teaching artificial intelligence in different educational levels in Bulgaria and to share and analyse the results.

The rest of the article is organized as follows: Section 1 provides a brief overview of research in this area. Section 2 discusses our approach to AI education in secondary school and in university. Section 3 aims to share their experience and presents the results from conducted experimental training. Finally, section 4 concludes the contribution.

\section{RELATED WORKS}

Digital technologies and computer science in particular have contributed greatly to the scientific and technological development of modern society. The term Computational Thinking (CT) is used to denote key ideas in computer science and computer science (Bocconi, 2016). This topic is becoming increasingly relevant in the field of education at all levels of education. The importance is determined not only by the content considered, but also by the positive impact that its study can have on the development of general thinking skills (Guggemos, 2021).

As can be seen from Figure 1 in computational thinking, different concepts and approaches are used, which include different aspects of analytical knowledge (logic, algorithms, modelling, abstractions, evaluation), as well as the approaches for their achievement (thinking, creation, permanence, cooperation, etc.).
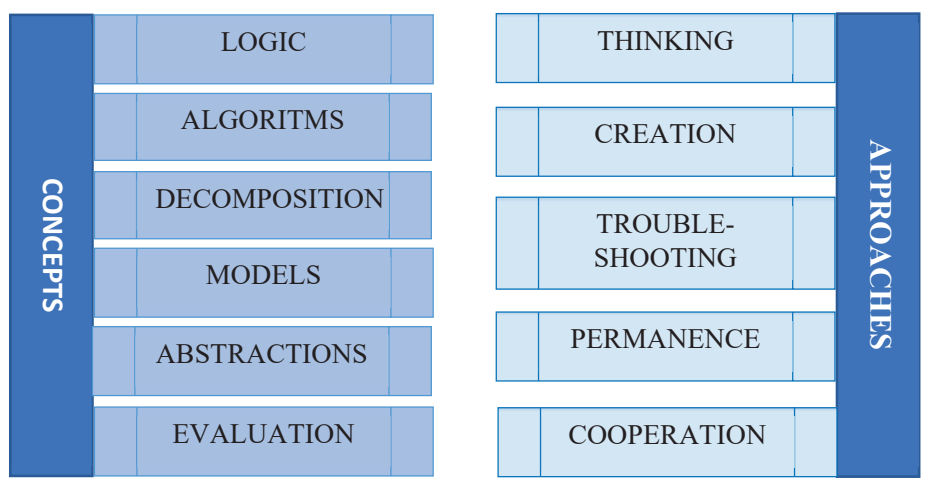

Fig u re 1. Computational thinking. Concepts and approaches

S ource: Own work.

Computational thinking is the subject of research in pedagogical science. It is built gradually in the process of learning at all educational levels. Artificial intelligence is 
a discipline whose approaches, goals and objectives contribute most to the development of computational thinking (Harangus, 2020).

The importance of AI training presupposes the creation of packages of strategic documents. According to the European Community's White Paper on Artificial Intelligence (White Paper On Artificial Intelligence - A European approach to excellence and trust, 2020), more than $€ 20$ billion in funding is provided each year under the Digital Europe, Horizon Europe and European Structural and Investment Funds for the development of skills needed to work in the field of AI and to adapt the education systems of individual European countries. The report of the Committee on Culture and Education to the European Parliament on the application of Artificial Intelligence in education (Tuomi, 2020) published in 2020 provides a thorough analysis of the need to train professionals to develop and apply intelligent approaches in various areas of modern business and services.

Bulgaria has also adopted a Concept for the development of Artificial Intelligence until 2030 (Concept for the development of Artificial Intelligence in Bulgaria until 2030). The document examines the potential of AI for smart growth and a prosperous democratic society and identifies as a priority "the creation of knowledge and skills for the development and use of artificial intelligence". On this basis, the Bulgarian Ministry of Education and Science approved a basic curriculum for AI, which can be used in the education of students in compulsory, profiling, elective and extracurricular training from various schools, classes and forms of education.

These strategic documents justify the need for enhanced formal and informal learning of AI at all levels of education. Universities have expanded their educational programs to this level of competence. In the last few years, the study of artificial intelligence has been introduced in different countries in different types of schools and at different educational levels (Holmes, 2019).

\section{OWN APPROACHES}

In recent years, in parallel with the development of the reference architecture of virtual physical space (Stoyanov, 2018) and its adaptation for e-learning (VES) (Stoyanov, 2020), the team of the DeLC laboratory at the Faculty of Math and Informatics at Plovdiv University developed a comprehensive concept for studying AI in school (Glushkova, 2020) and university education.

AI training at school is a challenge for the pedagogical community. The results shared by experts in different countries are impressive, but significant problems are identified (Balaganur, 2019), some of which are:

- The training is conducted in different schools, different classes and in different forms. The fact is that training in an inappropriate curriculum can greatly compromise the learning process.

- Lack of connection with students' knowledge of other subjects is a problem that can lead to excessive abstraction of the curriculum.

- In AI training it is necessary to apply other approaches and other style of training for which there are no trained teachers. Insufficient teacher training 
leads to excessive complication of the teaching material and to demotivation of the students.

To solve some of the problems, our team applies the following approach:

- Creating a basic curriculum with clearly defined modules (Introduction to AI, Solve problems with search, Knowledge and semantic modelling, Selected topics from "modern" AI). This curriculum is approved by the Ministry of Education and provides for formal education from $8^{\text {th }}$ to $12^{\text {th }}$ grade. Separate modules can be used to train different groups of students in interest clubs.

- Structuring the curriculum according to the traditional school methodology and development of teaching aids. This greatly assists teachers in the process of their prior preparation.

- Providing various interdisciplinary links with other subjects and the life experience of students and creating a system of learning tasks for the main topics of the curriculum. This increases the motivation and activity of all participants in the learning process.

- Organizing the process of preparation and current qualification of teachers. The solution of this task is realized together with the university and other non-governmental organizations, as well as with the participation in national and international projects under the above-mentioned European programs and structural funds.

Unlike school education, AI training has a long tradition in universities. The accumulated experience and the motivated interest of the university students, especially in the field of computer science, make this process natural and effective (HinojoLucena, 2019). However, new trends require continuous improvement and change of curricula and learning approaches. The fact is that the development of intelligent systems operating with knowledge is impossible without the intelligent structuring of this knowledge. Attention is usually paid to the intelligent behaviour of programs, but the extremely important topic of structuring knowledge is greatly underestimated. In this sense, our team has made some changes in the teaching approaches of this discipline, relying on the structuring of knowledge, semantic modelling and logical programming. The basic algorithms and concepts of classical and modern AI are presented and considered in this aspect.

\section{RESULTS AND ANALYSES}

Let's look at the results of the training conducted at school and university. In order to make a correct analysis, we will consider only the formal training conducted with all schools and university students in their courses. The reason to neglect (for now) the training in various elective courses and interest clubs is that in these groups only motivated and active learners participate, which naturally leads to higher results.

\subsection{Results and analyzes of AI training in school education}

During this school year in Plovdiv district we introduced experimental training in Artificial Intelligence in the specialized training of XI grade, profile "Software and Hardware Sciences" in two schools. The training is conducted according to the cur- 
riculum approved by the Ministry of Education and Science, using the developed textbooks on the first topic "Solving problems through search" (Stoyanov, 2019). 62 students participated in the experiment. In the course of the training we conducted several studies, the results of which are presented below.

To the questions Q1: "Do you think that studying AI is useful for your future development?" And Q2: "Does AI training motivate you to continue studying it next year?" $40 \%$ of students answered "Yes" and $22 \%$ with "Largely". Only $8 \%$ of the surveyed students answered "No". Also, a large part of the students (65\%) are motivated to continue studying AI next year.

In addition to questions related to students' attitudes to learning, the questionnaire included questions regarding the topics studied. The main goal of artificial intelligence education is for students to acquire knowledge, skills and competencs related to the basics of this discipline. As can be seen from Figure 2 students have acquired the necessary knowledge of the subject, the main tasks and role in the development of modern society; knowledge of the main characteristics and features of the Fourth Industrial Revolution; they have mastered the basic algorithms for searching in the "state space" and have understood the basic characteristics and possibilities of applying evolutionary strategies in solving problems.

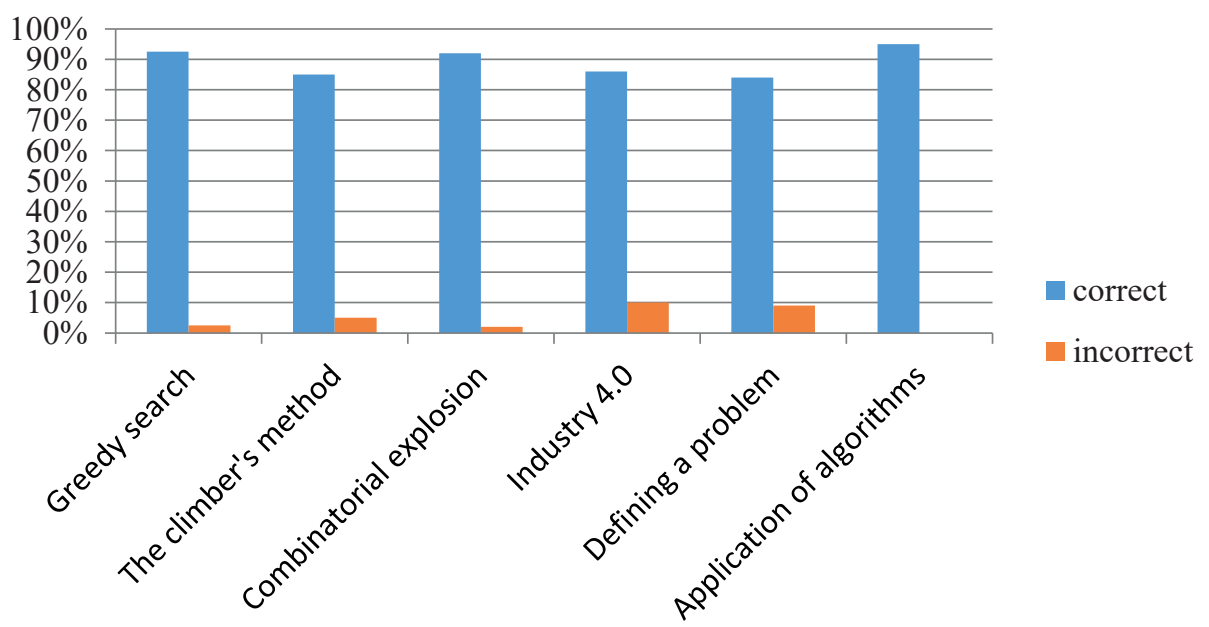

F ig u r e 2. Students' knowledge and skills on the studied topics

Source: Own work.

Artificial intelligence is a multidisciplinary science that is related at various levels to mathematics, computer science, physics, chemistry, history, etc. Creating a system of learning tasks related to students' knowledge of other subjects is one of the key approaches used in teaching (Tabakova-Komsalova, 2020). Considering tasks for generating tourist routes, searching for a way out of a labyrinth, moving robots in a vegetable garden, generating an irrigated (irrigation) plan in the conditions of intelligent agriculture and modelling competitive game spaces are successful ways 
to apply formal algorithms for search and problem solving. This reduces abstraction and increases the interest, activity and motivation of students in the learning process. The answers of the students related to their opinion about the application of AI today and in the near future confirm once again the need and importance of teaching AI in school. Students think reasonably and set their expectations based on the basic principles and concepts studied during the year. In support of this, they share some of their ideas for the use of AI that would improve lives: "Robot capable of distributing patients in the hospital, AI analysis of radiography, decoding of the viral genome, COVID vaccine search"; "... with the advent of new technologies, there are likely to be those that have the ability to cure currently incurable diseases; remote medical examinations; medical robots performing precise operations impossible for humans"; “... digital personal assistants"; “... fully automated production of food, construction and industrial goods, intelligent agriculture"; “... robots in electronic security and the fight against misinformation"; “... smart homes with smart devices that save energy, and in smart cities to improve services and reduce congestion."

As can be seen from the students' answers, they understand that the development of digital technologies is related to artificial intelligence and its application in all spheres of life. They understand the need to study AI at school and want to continue their education in the coming years.

At the end of the school year we were provided with information about the assessments of students on the topics of the curriculum to achieve the didactic aims. The average success of all students is Very Good 4.81, as the fluctuations in different schools and classes is very small. From the obtained data we can conclude that the students have mastered the teaching material, they understood the main characteristics of the problems, acquired skills to solve these problems with the methods of AI, which achieves the goal and the expected learning outcomes. During the school year the students applied the search algorithms for solving various practical tasks through the studied programming languages in the obligatory profiled preparation.

\subsection{Results and analyses from AI training of university students in computer science}

At the university, the study was conducted with students majoring in specialities "Informatics" and "Software Engineering". The training is conducted with all fulltime and part-time students. The change of the curriculum justifies the need to learn the logical programming language Prolog. At the end of the 2020/2021 school year, a survey was conducted, the results of which will be presented below.

To the questions Q1: "Do you think that studying AI and logical programming is useful for your future development? and Q2: "Does AI training motivate you to continue studying and using it?" $61.43 \%$ of students answered "Yes", $15 \%$ with "To a large extent". With a resounding "No" only $4 \%$ of the surveyed students answered, and a large part of the students $(68 \%)$ were motivated to continue studying it and to engage in logical programming. The comparative analysis with the students' answers shows a high level of similarity, as the higher percentage of positive answers of the computer science students is completely justified (Table 1). 
Table 1. Comparative analysis of the answers of school and university students

\begin{tabular}{|c|c|c|c|c|c|}
\hline University/Schools & $\begin{array}{c}\text { Number } \\
\text { of } \\
\text { students }\end{array}$ & $\begin{array}{c}\text { Q1 } \\
\text { Yes } \\
(\%)\end{array}$ & $\begin{array}{c}\text { Q1 } \\
\text { Largely } \\
(\%)\end{array}$ & $\begin{array}{l}\text { Q1 } \\
\text { No } \\
\text { (\%) }\end{array}$ & $\begin{array}{l}\text { Q2 } \\
\text { Yes } \\
(\%)\end{array}$ \\
\hline \multicolumn{6}{|c|}{ University students } \\
\hline $\begin{array}{l}\text { Plovdiv University, } \\
\text { Specialty „Informatics““ }\end{array}$ & 47 & $60 \%$ & $14 \%$ & $4 \%$ & $67 \%$ \\
\hline $\begin{array}{l}\text { Plovdiv University, } \\
\text { Specialty "Software engineering" }\end{array}$ & 96 & $63 \%$ & $16 \%$ & $4 \%$ & $69 \%$ \\
\hline \multicolumn{6}{|c|}{ School students } \\
\hline School I & 22 & $40 \%$ & $20 \%$ & $9 \%$ & $64 \%$ \\
\hline School II & 40 & $41 \%$ & $23 \%$ & $7 \%$ & $66 \%$ \\
\hline Total & 205 & $55 \%$ & $17 \%$ & $5 \%$ & 90 \\
\hline
\end{tabular}

Source: Own work.

In addition to questions related to students' attitudes to learning, we included in the questionnaire questions related to the topics studied in the AI course. The percentage of correct answers is presented in Figure 3.

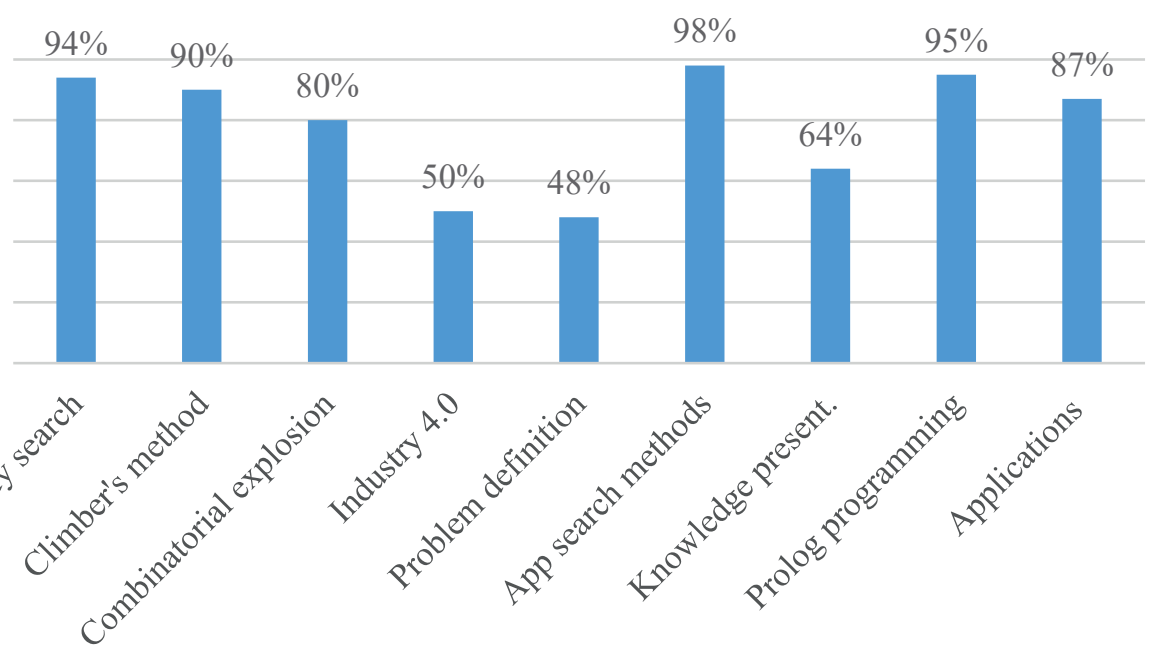

F ig u r e 3. Learning outcomes on various topics in \%

Source: Own work.

Along with the questions related to the assimilation of the study material, the students were asked several additional questions to establish the existence of links with other scientific and applied activities. Students think reasonably and set their expectations based on basic principles and concepts. They understand that the development of digital technologies is related to artificial intelligence and its application in all spheres of life. They understand the need to study AI and want to develop in this field. 
Figure 4 presents a diagram of the average grade in AI courses before and after applying the presented approach. There is a significant increase in the average success of students, which is largely due to their increased motivation and activity.

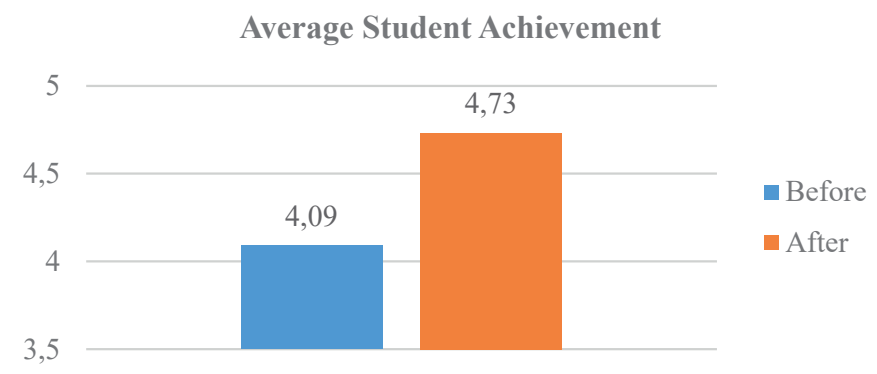

F ig u re 4. Average university student achievement before and after application of new approaches

Source: Own work.

The distribution of grades at the end of AI training in the computer specialties of PU "Paisii Hilendarski" before and after the application of the presented approach are visualized in Figure 5. The shift of the Gaussian distribution to the right explains the relatively high average success (4.73) after the end of 2020/2021 school year.

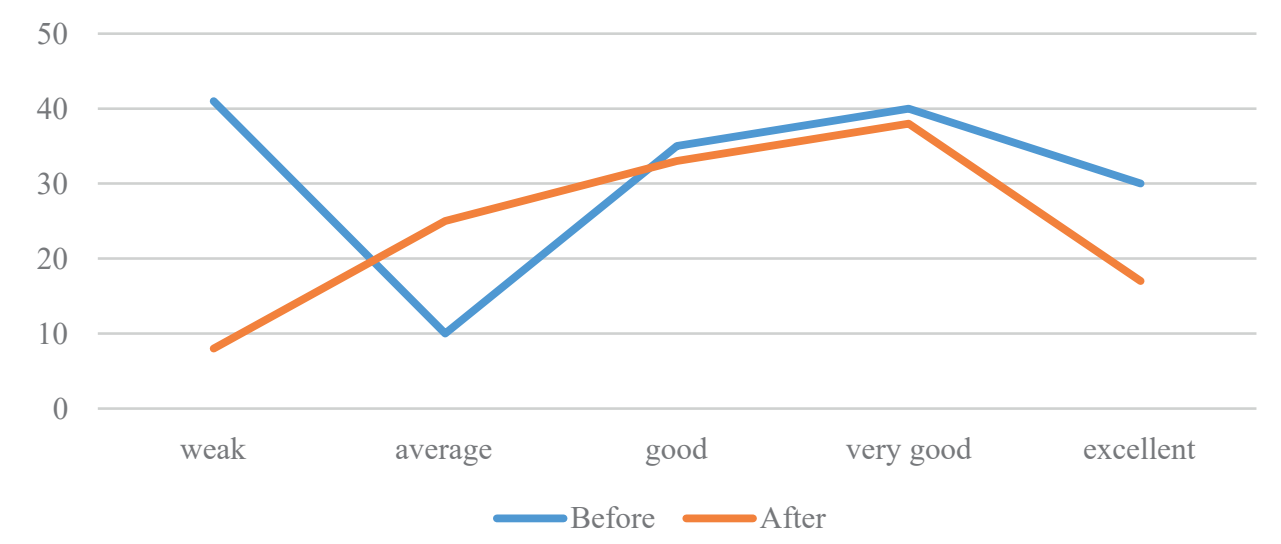

F ig u re 5. The assessment of students before and after the application of the presented approach

S ou r e: Own work.

Teacher training is perhaps the most important task in this process. To a large extent, these teachers did not study AI during their university education. The AI topic is specific and in order to conduct effective student training, continuous and in-depth teacher training is required. In the last three years, our team has organized qualification courses for 42 teachers, as follows: 18 participants in a course of 16 lessons and 24 - in a course of 60 lessons. About 50\% of teachers teach in a specialized high school; $25 \%$ - in a vocational school, and $12.5 \%$ - in a general education school. 
A survey was conducted, according to which the maintenance qualification courses (up to 32 hours) are extremely insufficient. They say that despite the textbooks, they do not feel safe enough in their work and want to continue their education in more depth.

From the surveys we can conclude that teachers are motivated to teach this subject in school because they believe that it is useful and promising for their students. This, of course, reflects on the desire of teachers to continue their education by studying other topics of classical and "modern" artificial intelligence. They shared that they want to deal with robotics, machine learning and various AI applications.

\section{CONCLUSION}

The formation of computational thinking is a process that is closely related to the teaching of artificial intelligence in secondary school and university. The approaches are different and are related to the characteristics of the respective learners. The results of the formal compulsory education in the experimental groups of university and school students are similar, which gives grounds for the conclusion that the educational content, teaching methods and approaches are suitable for achieving the main didactic goals.

When analysing the training in elective courses and interest clubs at the university and in the high school, we find much better results, which are undoubtedly related to the higher motivation of both the learners and the trainers. The preparation of teachers is a key task on which the success of AI training and development of computational thinking in secondary school education largely depends (Moudgalya, 2021). The future plans of the team are to develop a complete package of textbooks for all major topics of the school curriculum and to continue to improve the chosen approach to university student learning. It is necessary to create an extended curriculum and teaching resources for teacher training to train students from different schools, classes and forms of education in the field of AI.

\section{ACKNOWLEDGEMENTS}

The results published in this article are part of a study conducted with the financial support of project FP21-FMI-002 "Intelligent Innovative ICT in Research in Mathematics, Informatics and Pedagogy of Education" of the Scientific Fund of Plovdiv University "P. Hilendarski” in Bulgaria.

\section{REFERENCES}

B a la g a n u r, S. (2019). The Problem with Including AI in School Curriculum. Analytic India Magazine. Retrieved from https://analyticsindiamag.com/the-problem-with-including-ai-in-school-curriculum/ (accessed 1 June 2021).

Bocconi, S., Chioccariello, A., Dettori, G., Ferrari, A., Engelhardt, K., Ka m pylis, P., \& P u n ie, Y. (2016). Developing Computational Thinking: Approaches 
and Orientations in K-12 Education. Proceedings from the EdMedia + Innovate Learning, (13-18), Vancouver, BC, Canada, Jun 28, 2016, ISBN 978-1-939797-24-7.

Concept for the development of Artificial Intelligence in Bulgaria until 2030 Retrieved from https://strategy.bg/FileHandler.ashx?fileId=23684.

Glushkova, T., Stoyanov, S., Tabakova-Komsalova, V., GrancharovaHristova, M., \& Krasteva, I. (2020). An Approach to Teaching Artificial Intelligence in School. In E. S my r nova-Trybulska (Eds.). Innovative Educational Technologies, Tools and Methods for E-learning (pp. 257-267), 12. https://doi.org/10.34916/ el.2020.12.22.

Guggemos, J. (2021). On the predictors of computational thinking and its growth at the high-school level. Computers \& Education, 161, 104060, ISSN 0360-1315. https://doi. org/10.1016/j.compedu.2020.104060.

Ha r a n g us, K. \& Kát a i, Z. (2020). Computational Thinking in Secondary and Higher Education, Procedia Manufacturing, 46, 615-622. ISSN 2351-9789, https://doi.org/10.1016/j. promfg. 2020.03.088.

Hinojo-Lucena, F.-J., A znar-Díaz, I., Cáceres-Reche, M.-P., \& RomeroRodríguez, J.-M. (2019). Artificial Intelligence in Higher Education: A Bibliometric Study on its Impact in the Scientific Literature. Education Sciences, 9, 51. https://doi.org/ 10.3390/educsci 9010051.

Holme s, W., B i a li k, M., \& F a d el, C. (2019). Artificial Intelligence In Education Promises and Implications for Teaching and Learning. Boston: The Center for Curriculum Redesign, USA, MA, 02130, ISBN-13: 978-1-794-29370-0, 2019.

Moudgalya, S., Yad av, A., S a nd s, Ph., Vogel, S., \& Z a m a n sky, M. (2021). Teacher Views on Computational Thinking as a Pathway to Computer Science. In Proceedings of the $26^{\text {th }}$ ACM Conference on Innovation and Technology in Computer Science Education V. 1 (ITiCSE '21), New York, NY, USA (pp. 262-268). https://doi.org/10.1145/3430665.3456334.

S ch w a b, K. (2016). The Fourth Industrial Revolution. Crown Business, USA.

St oy a nov, S. \& Glu sh kova, T. (2020). An Approach to E-learning in the Virtual Education Space. CEUR Workshop Proceedings, 2770 (pp. 55-64). ISBN 1613-0073.

St oy a nov, S., Glu sh kova, T., \& Tod or ov, J. (2019). Artificial Intelligence. Solve problems through search. [Izkustven intelekt. Reshavane na problemi posredstvom tarsene]. Sofia: Izkustva. ISBN: 9786197243871.

Stoyanov, S., Stoyanova-Doycheva, A., Glushkova, T., \& Doychev, E. (2018). Virtual Physical Space - an architecture supporting internet of things applications. $X X$ th International Symposium on Electrical Apparatus and Technologies SIELA 2018. IEEE, 3-6 June, Bourgas, Bulgaria. DOI: 10.1109/SIELA.2018.8447156.

Tabakova-Komsalova, V., Glushkova, T., Gra ncharova-Hristova, M., \& $\mathrm{Kr}$ a st e va, I. (2020). Learning tasks in Artificial intelligence education. Educations and Technologies, 11/1, 233-240. ISSN 1314-1791, https://doi.org/10.26883/2010.201.2292.

Tu o m i, I. (2018). The Impact of Artificial Intelligence on Learning, Teaching, and Education. M. Cabrera, R. Vu orikari, \& Y. P un i e (Eds.). Luxembourg: Publications Office of the European Union. ISBN 978-92-79-97257-7, https://doi.org/10.2760/12297, JRC113226.

Tu o mi, I. (2020), Research for CULT Committee - The use of Artificial Intelligence (AI) in education, European Parliament. Retrieved from https://www.europarl.europa.eu/ 
RegData/etudes/BRIE/2020/629222/IPOL_BRI(2020)629222_EN.pdf. (accessed 1 July 2021).

White Paper On Artificial Intelligence - A European approach to excellence and trust, 2020. Retrieved from https://ec.europa.eu/info/sites/info/files/commission-white-paper-artifi cial-intelligence-feb2020_bg.pdf. 